\title{
Lidar Application for Mapping and Robot Navigation on Closed Environment
}

\author{
I. Maulana, A. Rusdinar, and R. A. Priramadhi \\ School of ElectricalEngineering, Telkom University, Bandung, 40287, Indonesia \\ *anggarusdinar@telkomuniversity.ac.id \\ Manuscript received Jan 22, 2018; revised May 4, 2018; accepted Jun 1, 2018
}

\begin{abstract}
Mapping and navigation on robots are now widely applied in areas such as industry, home appliances, military, exploration and automated vehicles. Mapping and navigation of robots are essential for use in closed environments that are hard to reach by humans. With the mapping and navigation on the robot can allow the robot to recognize the surrounding environment.Data from LIDAR sensors can be converted to maps of the surrounding environment and can be used as an estimate of the position of robots in a closed environment. The distance data from the LIDAR sensor and the LIDAR sensor position status data are converted into Cartesian axes and processed into local maps. Localization using LIDAR sensors are used as a reference to updating global maps.
\end{abstract}

Keywords: Global Map LIDAR; Localization; Local Map; Mapping and Navigation.

DOI: https://doi.org/10.25124/jmecs.v4i1.1696

\section{Introduction}

Environmental mapping is one of the most important aspects of robotics studies when dealing with localization, positioning, automatic navigation, and also search and rescue [1]. Environmental mapping can be used for narrow caves, low oxygen underground passageways, unknown environments that humans cannot reach. In addition, the number of manufacturing jobs, mining, and industry that are still manually done by humans are very prone to the occurrence of accidents. Therefore it takes a tool that can do map and navigation automatically so that the robot can replace human workers.

To be able to create a map of environment requires sensors that have a high level of accuracy and far reach. LIDAR is one of remote sensing technology that has the potential to help (map, monitor, and estimate spatial element locations) of many fields/applications related to the provision of geospatial databases [2]. Due to data density and high accuracy so LIDAR sensor is very suitable to be implemented in robot mapping and navigation. Many researchers reported has used laser range finders in their system such as M. A. Markom, A. H. Adom, E. S. M. M. Tan, S. A. A. Shukor, N. A. Rahim, A. Y. M. Shakaff [1], it uses RP Lidar sensor to create the mapping with a mobile robot. A. Rusdinar that use laser range finders based to fix error poses correction of mobile robot using particle filter [3] and a visionbased indoor localization method for autonomousVehicles [4].A. Rubinstein and T. Erez created a robot called LiTank which is a robot used for tunnels mapping using Lidar sensors made by Velodyne [5].

Automatic navigation of the robot is also required on the mapping environment so that the robot can run properly. Data from LIDAR can be mapped and used by robots to determine localization to the environment. Then the mapping data is used by robots for navigation and movement planning. In addition, data from LIDAR is also used to estimate the robot position required during mapping of the surrounding environment. Localization and road planning are fundamental to the problem of robotic navigation. To achieve successful navigation, the robot must be able to localize itself and produce a simultaneous environmental map (SLAM) [6].

The first objective of this research is to create a spinner for LIDAR sensors in order to scan the surrounding environment with a range of 360 degrees using only one sensor only. The second goal is to create an environmental mapping system based on data from LIDAR sensors with interfaces for monitoring. The third goal is the robot positioning based on the comparison of the results of two scans. The final goal is to visualize the navigation based on the map you have created.

\section{System Design}

To be able to do the mapping and navigation in need of several stages of data collection from the sensor, robot position estimation, map creation and 
Maulana et al. / Journal of Measurement, Electronics and Communication Systems

navigation. The sensor is rotated 360 degrees using a stepper motor. Arduino retrieves data from LIDAR Lite V3 sensor using PWM communications. The data from the sensor is taken each step of the stepper motor rotation. Data from the sensor is sent by Bluetooth and the data is taken using serial communication by Matlab software. After the data obtained, then Matlab change the data to be processed into a map and navigation. Each movement of the stepper motor is controlled by a command from Matlab which is sent via Bluetooth with serial communication.

Figure 1 shows a flow chart of the mapping and navigation system. The first program run Matlab software connects serial communication with Arduino. Then Matlab gives Arduino command to move the sensor and send data every step. After the data obtained then the data processed by Matlab to make the map of probability. Then Matlab retrieves the data again and stored on different variables. The first data and newly processed data using the scan matching function to obtain a new robot position. Position and orientation data are then used to update the new data to a global map. The data retrieval process and global map updates continue until all environments are mapped. Once map mapped data previously obtained plus limits for robots with inflating map function. After that a graph of possible paths can be passed using the PRM function. Thereafter searched the shortest path based on the map and the previous PRM.

\subsection{Occupation Grid}

The Occupancy Grid reflects the multidimensional map of its environment (usually 2D or 3D) into the cell, where each cell stores its probabilistic state value [7]. Environmental information can be drawn from distance sensor data, camera and bump sensors commonly used to determine obstacles in the robot environment. There are 2 representations of the Occupancy Grid map of Binary Occupancy Grid andProbability Occupancy Grid.

The Binary Occupancy Grid uses the True value to represent the occupied workspace (obstacle) and the False value to represent the free workspace. This box shows where the obstacles are and whether the robot can move through that space. While probability occupancy grid uses probability values to create more detailed map representations. This representation is the preferred method for using the Residential Grid. This grid is usually referred to simply as a dwelling. Each cell in the Residential Grid has a value that represents the probability of the cell's occupancy. A value close to 1 represents a high certainty that the cell contains obstacles. A value close to 0 represents the certainty that the cell is not occupied and barrier-free [8].

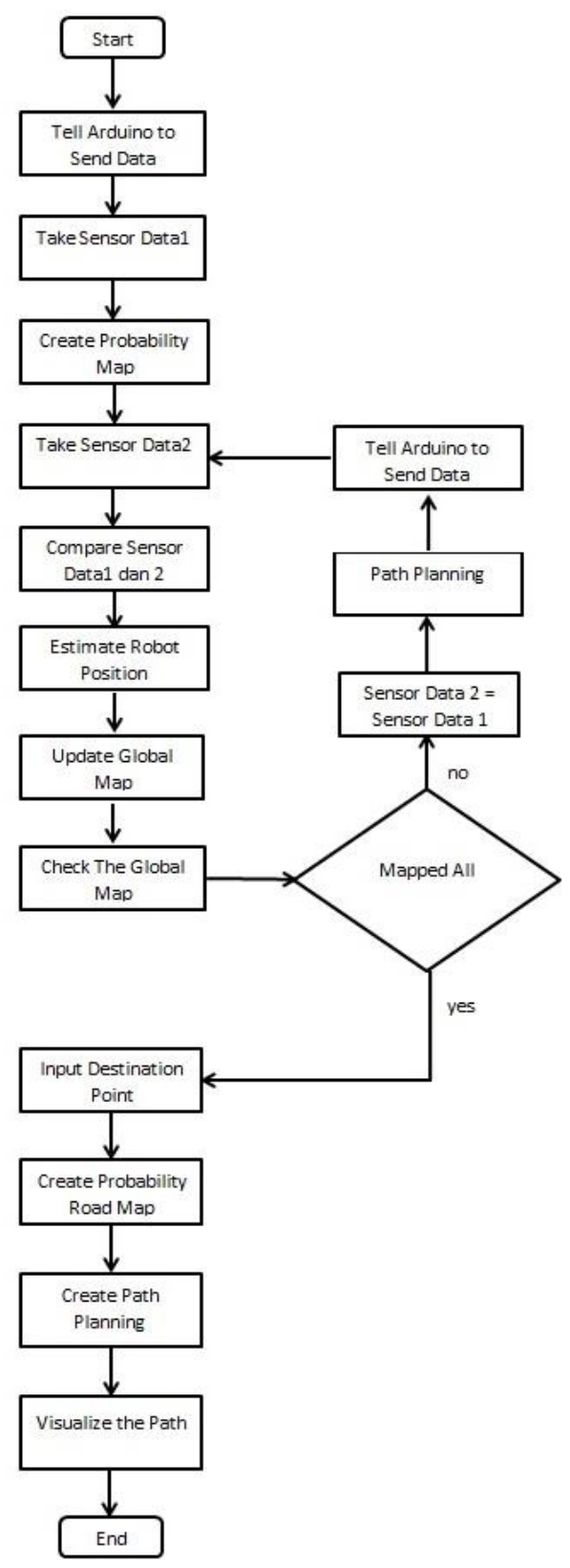

Fig.1.Flowchart of System

\subsection{Probability Road Map}

Probability Road Map (PRM) is a network graph of paths that may be present in a map determined by a free and unimpeded space [9].Basically, the way PRM works is to take a random sample from the map, each sample is checked whether it is in an empty room or barrier-free. Then made local planning then each plan is connected to each other based on the nearest. 
Maulana et al. / Journal of Measurement, Electronics and Communication Systems

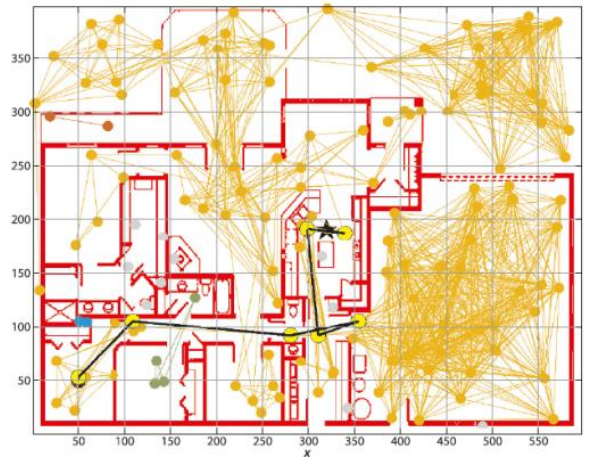

Fig. 2.PRM and minimum robot path planning[10]

There are two stages to PRM. First is the construction stage of making a road map approaching the robot movement that can be done on the environment. Initially a random configuration is created and then connected to some of its neighbors, usually the closest one is less than the specified distance. Second is the query stage of the initial position configuration and the end position is connected with the graph according to theDijkstra Algorithm to determine the shortest path.

\subsection{Hardware Design}

Figure 3 shows the connection between the components that exist in the system. First, the sensor data is taken by the Arduino through the slip ring so that the sensor can rotate 360 degrees continuously. Then Arduino controls the motion of a stepper motor using a motor driver. Data from sensors is sent via Bluetooth communication to PC. Then the PC with Matlab software processes the data to become a map.

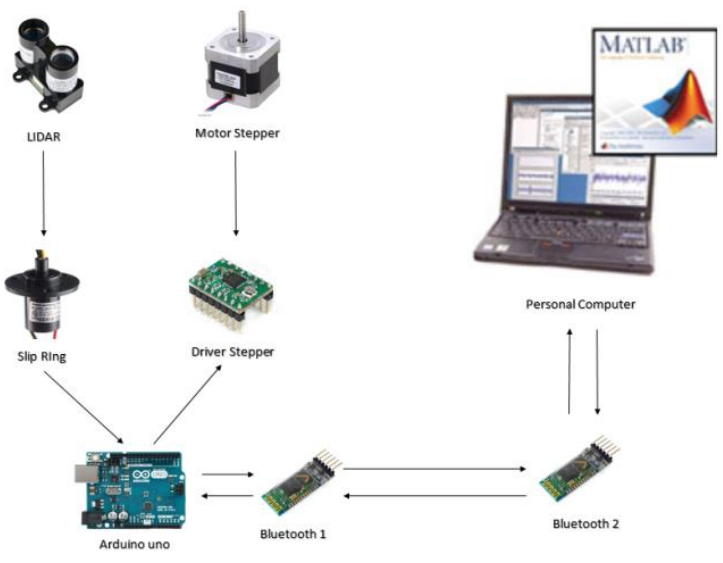

Fig. 3. Connection of Hardware Component

In the design of the lidar spinner there are several important parts as in Figure 4 which will affect the quality of this Project. First is a Stepper dish and a LIDAR disk connected by a rubber belt. The comparison between the disks is 1 : 2 so with the stepper motor resolution of only 200 step can be increased to 400 step so that the mapping can be better again later.

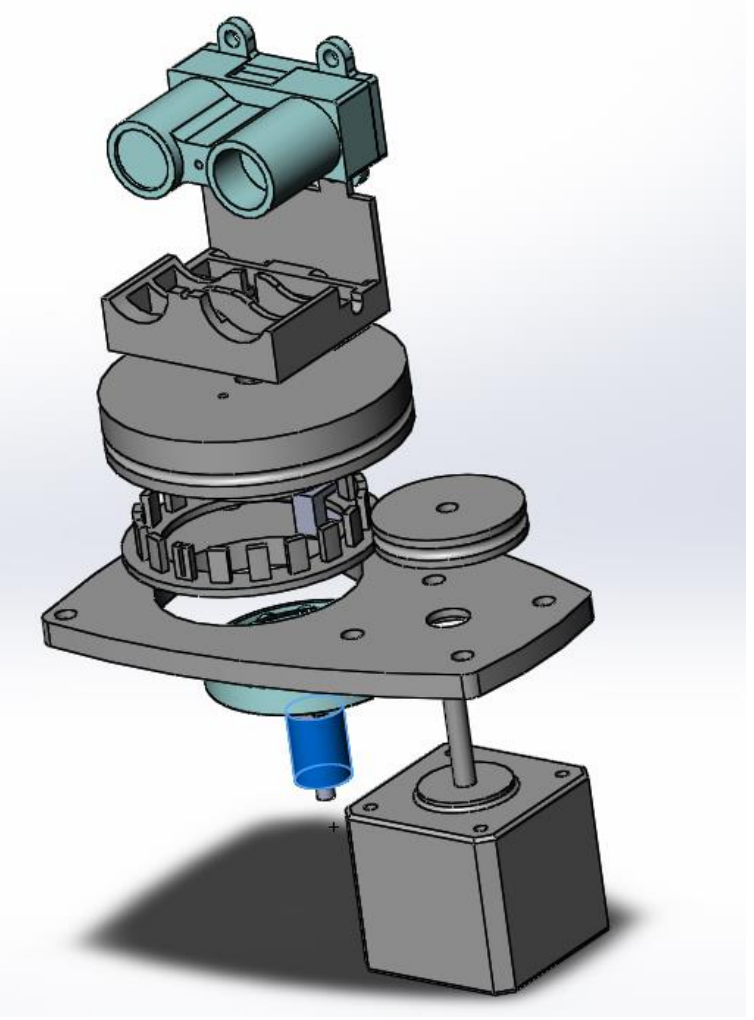

Fig. 4.Design of Hardware

Second is the slip ring is a component that connects the 360 degrees lidar sensor with Arduino uno. This component is very important because this component makes the sensor connector cable is not twisted when rotated. The third is the encoder is a tool to measure angle orientation on the sensor and can be used for feedback motor speed control stepper.

\subsection{Lidar Lite V3 and Data Collection}

LIDAR Lite V3 is a low-cost laser rangefinder sensor developed from garmin. this sensor has a great range and good accuracy. this sensor measures the distance by calculating the time difference between sending a laser beam with its reception after it is reflected an object.

There are two basic configurations for this device, I2C and PWM. in this project used PWM configuration to take distance data from the sensor. For angle, data retrieval is taken based on the calculation of each step of the driving stepper motor. LIDAR Lite V3 sensor mounted on the sensor spinner connected with stepper motor using a belt.the design of the sensor spinner is made on solidwork software which is then printed using plastic material.Figure 4 shows the LIDAR mounted on the printed spinner and a motor stepper. 
Maulana et al. / Journal of Measurement, Electronics and Communication Systems

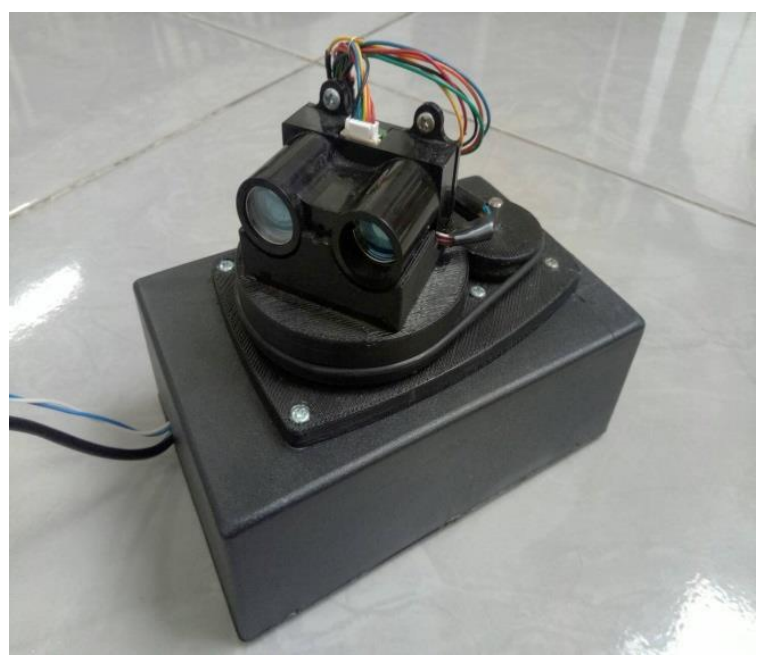

Fig. 5 Printed LIDAR and Spinner

Data from lidar sensor is taken by by Arduino to then sent to PC via Bluetooth communication. The distance and angle data are then converted into cartesian form as follows :

i. convert degree to rad

$$
\theta_{\text {rad }}=\theta_{\text {deg }} \times \frac{\pi}{180}
$$

Where $\theta_{\text {rad }}$ denotes angle in radian and $\theta_{\text {deg }}$ is angle in degree.

ii. convert polar to cartesian

$$
\begin{gathered}
x=r h o \times \sin \left(\theta_{\text {rad }}\right) \\
y=r h o \times \cos \left(\theta_{\text {rad }}\right)
\end{gathered}
$$

Where $x$ is position in $\mathrm{x}$-axis and y position is $\mathrm{y}$ axis. Map creation and navigation are made in Matlab software that has loaded robotics system toolbox used in this research.

\section{Testing and Analysis}

This test purpose is to know the accuracy of distance reading by the LIDAR sensor at a specified distance compared to the actual distance measured, the reading result at a certain angle range,the effect of reading distance on a particular color the effect of distance reading on certain types of surface materials measured, see the visualization results of LIDAR sensor scans rotated 360 degrees compared to the actual form of test environment, view mapping visualization results from sensor data captured many times and see if the mapping results are eligible for robot navigation.

Based on the data on table 1 obtained that the measurement on the smaller the results of the measurement the better. Based on error measurement result concluded that good reading is the measurement of distance less than 20 meters. Based on the LIDAR Lite V3 sensor datasheet that the sensor reading limit is 40 meters with the effectiveness of $75 \%$ has been in accordance with the test results. On testing the distance of more than 20 meters there is error readings so that in the table in the input numbers that have been eliminated error value. It is therefore concluded that a good reading limit for mapping with LIDAR Lite V3 sensor is 20 meters while its minimum distance is either $75 \mathrm{~cm}$ or adjusted to the dimensions of the robot used.

Table 1. Sensor Distance Reading Results

\begin{tabular}{|c|c|c|c|c|c|}
\hline \multirow{2}{*}{$\begin{array}{c}\text { Sensor } \\
\text { Read }\end{array}$} & \multicolumn{5}{|c|}{ Real Measured Value $(\mathrm{cm})$} \\
\cline { 2 - 6 } & 50 & 75 & 1200 & 2000 & 3000 \\
\hline 1 & 49 & 64 & 1200 & 1999 & 2971 \\
\hline 2 & 59 & 73 & 1216 & 2013 & 3006 \\
\hline 3 & 65 & 75 & 1217 & 2022 & 3021 \\
\hline 4 & 63 & 76 & 1226 & 1991 & 8270 \\
\hline 5 & 66 & 78 & 1208 & 2017 & 2941 \\
\hline 6 & 63 & 74 & 1219 & 2023 & 2994 \\
\hline 7 & 65 & 72 & 1221 & 1997 & 3001 \\
\hline 8 & 62 & 77 & 1206 & 2033 & 2980 \\
\hline 9 & 65 & 73 & 1230 & 2004 & 2958 \\
\hline 10 & 60 & 74 & 1214 & 2004 & 2974 \\
\hline $\begin{array}{c}\text { Averag } \\
\text { e }\end{array}$ & 61. & 73. & 1215. & 2010. & 3511. \\
\hline $\begin{array}{c}\text { Standart } \\
\text { Devia- } \\
\text { tion }\end{array}$ & 5.0 & 3.8 & 9.1 & 13.4 & 1672. \\
\hline \multicolumn{7}{c}{} & & & & & 0 \\
\hline
\end{tabular}

Table 2. Distance Reading On Certain Surface Colors

\begin{tabular}{|c|c|c|c|c|c|}
\hline \multirow{2}{*}{ No. } & \multicolumn{5}{|c|}{ Color } \\
\cline { 2 - 6 } & Red & $\begin{array}{c}\text { Gree } \\
\mathrm{n}\end{array}$ & Blue & $\begin{array}{c}\text { Whit } \\
\mathrm{e}\end{array}$ & $\begin{array}{c}\text { Blac } \\
\mathrm{k}\end{array}$ \\
\hline 1 & 103 & 104 & 104 & 101 & 88 \\
\hline 2 & 103 & 105 & 106 & 103 & 99 \\
\hline 3 & 105 & 105 & 105 & 102 & 104 \\
\hline 4 & 114 & 105 & 105 & 102 & 105 \\
\hline 5 & 110 & 104 & 103 & 105 & 96 \\
\hline 6 & 102 & 103 & 105 & 104 & 101 \\
\hline 7 & 102 & 106 & 104 & 102 & 102 \\
\hline 8 & 105 & 103 & 103 & 103 & 98 \\
\hline 9 & 103 & 104 & 107 & 104 & 106 \\
\hline 10 & 102 & 104 & 106 & 101 & 103 \\
\hline $\begin{array}{c}\text { Averag } \\
\mathrm{e}\end{array}$ & 104. & 104.3 & 104. & 102.7 & 100.2 \\
\hline $\begin{array}{c}\text { Standart } \\
\text { Devia- } \\
\text { tion }\end{array}$ & 4.0 & 0.95 & 1.31 & 1.3 & 5.33 \\
\hline
\end{tabular}

Based on the table 2 of measurement data obtained that the color of the measured area can affect the sensor readings. 
Maulana et al. / Journal of Measurement, Electronics and Communication Systems

Table 3. Distance Reading On Certain Surface Material

\begin{tabular}{|c|c|c|c|c|c|}
\hline \multirow{2}{*}{ No. } & \multicolumn{5}{|c|}{ Material } \\
\cline { 2 - 6 } & Wall & $\begin{array}{c}\text { Plas- } \\
\text { tic }\end{array}$ & Wood & Iron & $\begin{array}{c}\text { Card- } \\
\text { board }\end{array}$ \\
\hline 1 & 81 & 87 & 84 & 102 & 101 \\
\hline 2 & 104 & 97 & 102 & 104 & 109 \\
\hline 3 & 103 & 106 & 101 & 103 & 110 \\
\hline 4 & 105 & 100 & 103 & 105 & 117 \\
\hline 5 & 106 & 103 & 102 & 103 & 118 \\
\hline 6 & 102 & 96 & 104 & 103 & 110 \\
\hline 7 & 100 & 101 & 101 & 109 & 111 \\
\hline 8 & 100 & 101 & 103 & 105 & 108 \\
\hline 9 & 107 & 100 & 102 & 106 & 106 \\
\hline 10 & 106 & 98 & 104 & 105 & 113 \\
\hline Average & 101.4 & 98.9 & 100.6 & 104.5 & 110.3 \\
\hline $\begin{array}{c}\text { Standart } \\
\text { Devia- } \\
\text { tion }\end{array}$ & 7.5 & 5.0 & 5.9 & 2.0 & 4.9 \\
\hline
\end{tabular}

Based on the table 3 data obtained that each material object that can be measured to influence the measurement results.

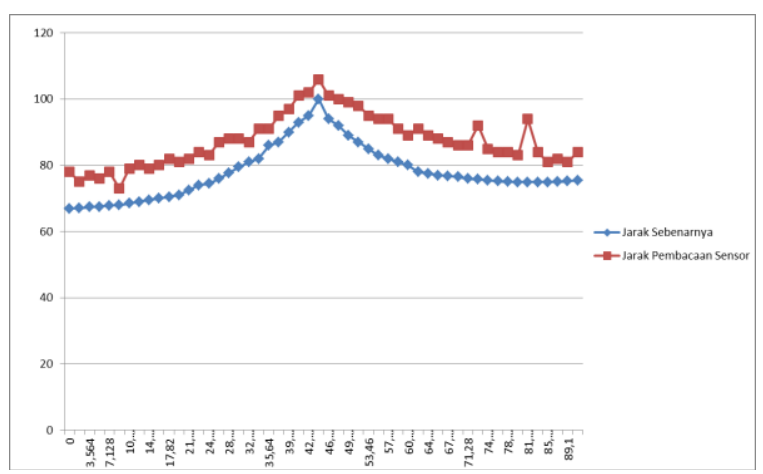

Fig. 6.Graph of sensor and distance measurement results
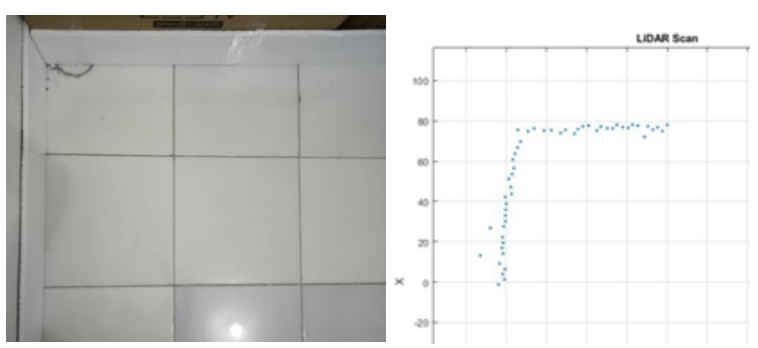

Fig. 7.Measurement Room and Ploting Result

Based on the Figure6 and 7,sensor measurement data has a level of accuracy is good enough to make mapping worthy. Error reading of the distance itself can be solved by making a map that is divided into boxes with a certain resolution.

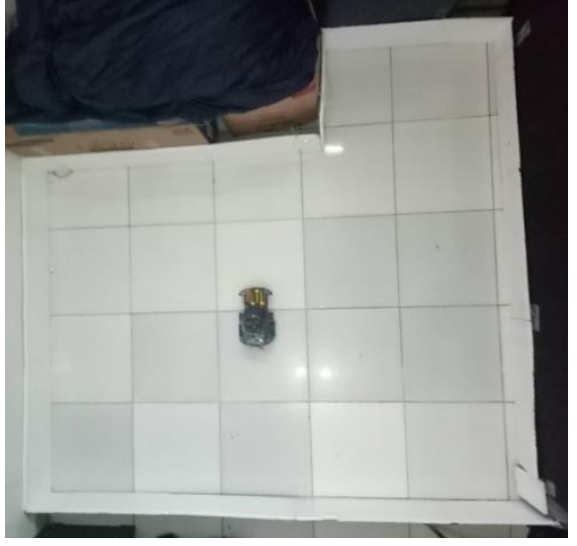

Fig. 8.Test room

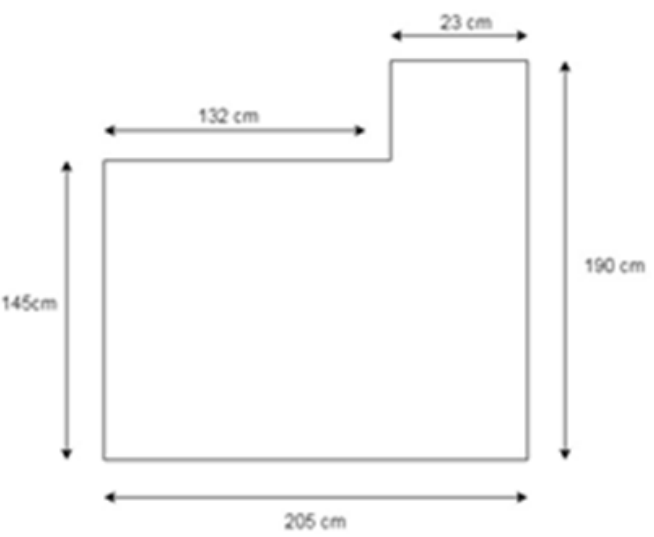

Fig. 9. Test room dimensions

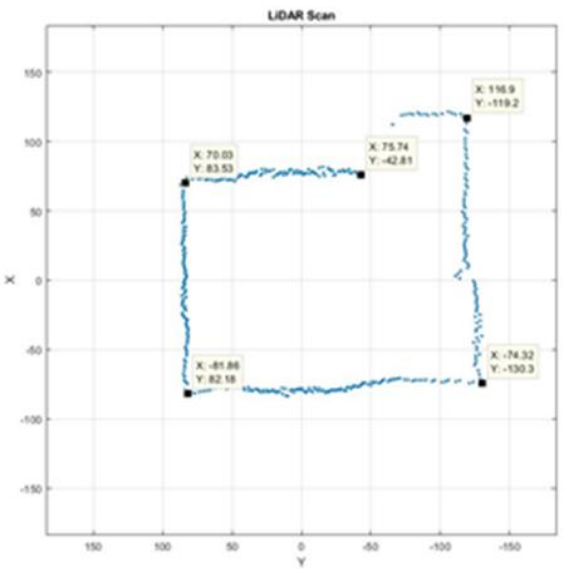

Fig. 10.Sensor Scan Mappingresults

Based on the results of the scan data of figure 9 obtained that the form of visualization of figure 10 from the original room form of figure 8 . The form of visualization is not a straight line is the result of sensor readings error because of the sensor readings less than 1 meter in accordance with the calculation of error. By reducing the $\mathrm{X}$ coordinates on the left side, the right side length based on the visualization is $191.22 \mathrm{~cm}$ or 
Maulana et al. / Journal of Measurement, Electronics and Communication Systems

has an error of $0.006 \%$ and on the lower side with the reduction of the Y coordinate value is $212.48 \mathrm{~cm}$ or has an error of $3.6 \%$. Based on the visualization obtained that dimension closer to the actual dimensions.
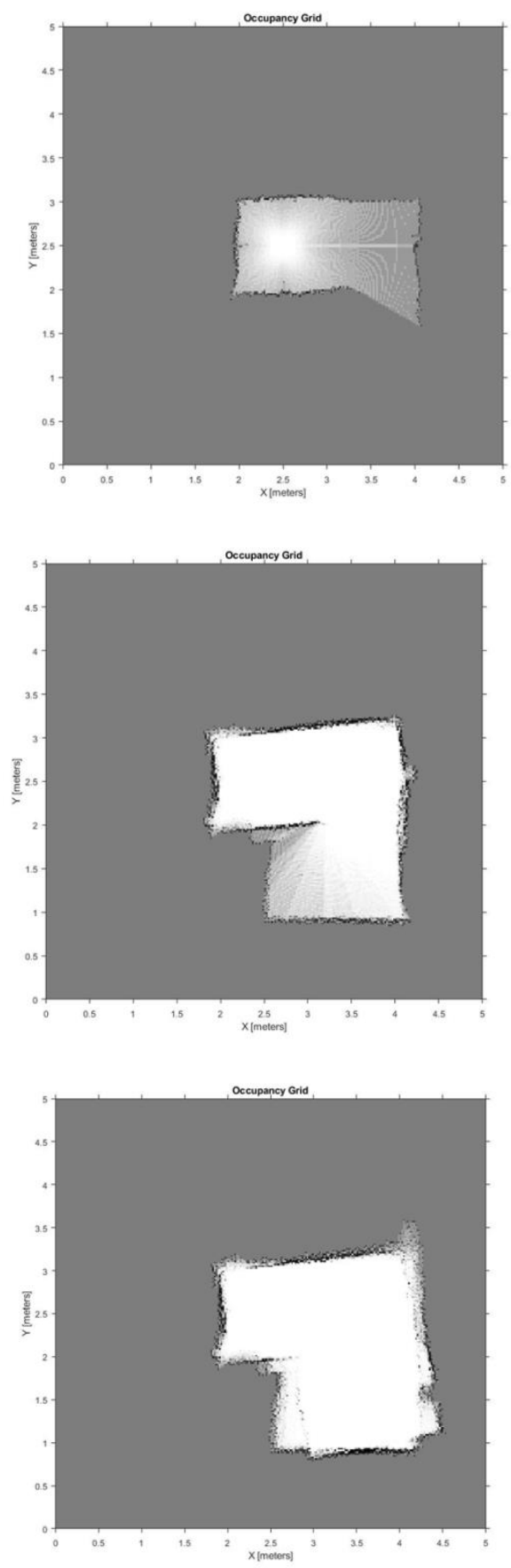

Fig. 11. $1^{\text {st }}, 10^{\text {th }}$ and $20^{\text {th }}$ steps of mapping

Based on the visualization of the mapping results on Figure 11 it can be seen that there is an error reading the orientation of the robot causing an error on the visualization of the mapping. Because the position and orientation estimation based on current and previous scan data, the resulting error is getting bigger and cause the mapping result the less good can be seen from the visualization result which is getting away from the actual shape at every step of mapping step.

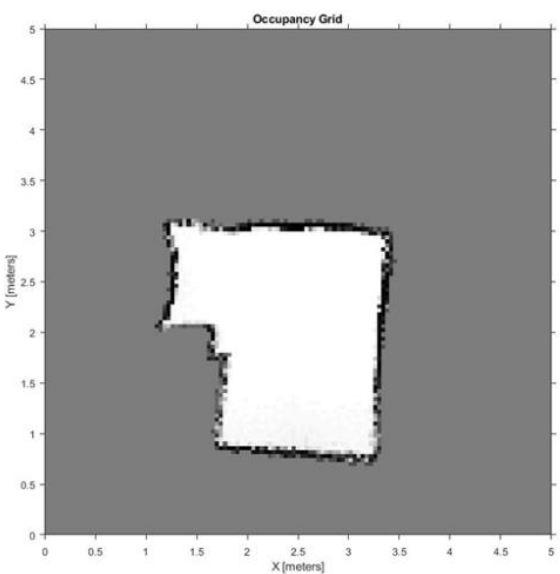

Fig. 12. Test room map

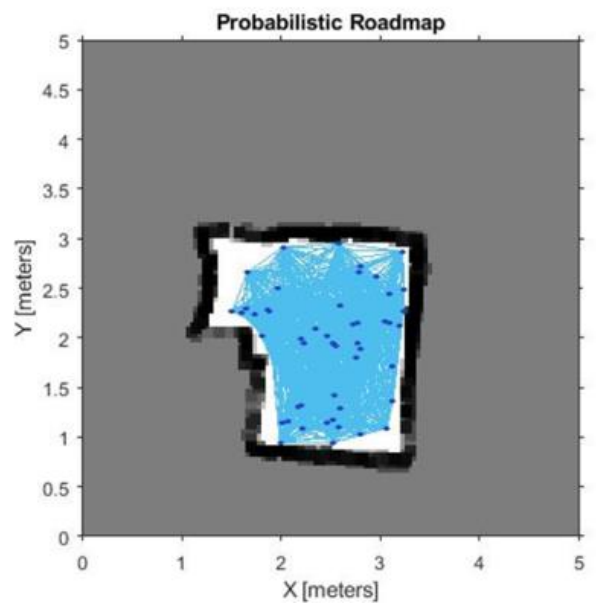

Fig. 13. PRM

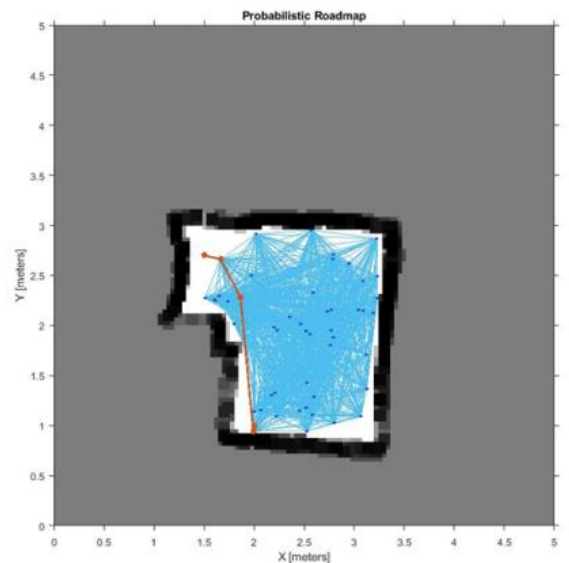

Fig. 14. Path planing

Based on the test results of Figure 12, 13 and 14 obtained that the map can be used as reference navigation robot. Once the path is obtained, the robot 
Maulana et al. / Journal of Measurement, Electronics and Communication Systems

can be controlled to follow the path. The determination of the number of nodes in the PRM will be better if more but the calculation time is longer.

\section{Conclusions}

From the results of testing and analysis obtained the conclusion of this Final Project that the sensor has a different error value for each distance read. A good distance to map is less than 20 meters. Measurements beyond good reading limits can lead to poorly mapped visualization forms. The colors and materials of the measurement medium can affect the accuracy of the reading of distance data. So that the color and shape variation in the actual environment can cause the environmental visualization becomes less good. Sensors have a good level of accuracy so that when visualized enough to represent the actual form of the environment. Positioning estimates using matching scans are poor because there are considerable errors during measurement. Estimation of orientation using scan matching is very bad. The distance between one scan and another scan must be close to reducing errors from position estimation and orientation. Error from position estimation and orientation can cause the mapping of the environment to be less good because the insertion of scan data that is not in accordance with it should.

\section{REFERENCE}

[1] M. A. Markom, A. H. Adom, E. S. M. M. Tan, S. A. A. Shukor, N. A. Rahim, A. Y. M. Shakaff, "A Mapping Mobile Robot using RP LIDAR Scanner". IEEE Transaction on Robotics and Intelligent Sensors, 2015

[2] E. Prahasta, "Pengolahan Data LIDAR". Bandung:Informatika,2015.

[3] Rusdinar. A, Kim. J., Kim. S., "Error pose correction of mobile robot for SLAM problem using laser range finder based on particle filter", Internation Conference of Control Automation and Systems (ICCAS), 2010.

[4] Rusdinar. A., Kim. S., Vision-Based Indoor Localization Using Artificial Landmarks and Optical Flow and a Kalman Filter, International Journal of Fuzzy Logic and Intelligent Systems Vol. 13, No. 2, June 2013, pp. 133-139.

[5] A. Rubinstein, T. Erez, "Autonomous Robot for Tunnel Mapping". International Conference on the Sciece of Electrical Engineering, 2016.

[6] N. Jain, Y. P. Kumar, K. S. Nagla, Comer Extraction From Indoor Environment For Mobile Robot Mapping. Presented at India Conference (INDICON), New Delhi, India, 2015.

[7] A. Elfes, "Using Occupancy Grids for Mobile Robot Perception and Navigation". IEEE Transaction on Computer, 1989.

[8] https://www.mathworks.com/help/robotics/ug /occupancy-grids.html [Accessed in 20 December 2017 20:19:00 WIB].
[9] https://www.mathworks.com/help/robotics/ug/ occupancy-grids.html [Accessed in 21 December 2017, 08:00:21 WIB]

[10] P. Corke, Robotics, Vision and Control Fundamental Algorithms in MATLAB. Berlin : Springer 2011.

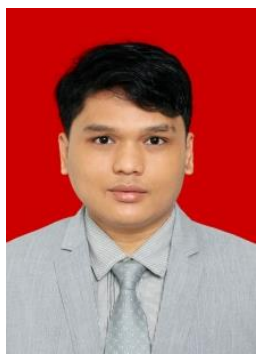

Ikhsan Maulana was born in Tasikmalaya, September $15^{\text {th }}$ 1995. Had graduated in High School 5 Tasikmalaya. Then continued to study in Electrical Engineering from Telkom University.

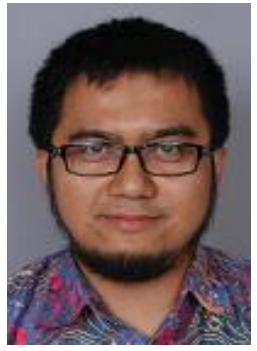

Angga Rusdinar received his B.Eng. degree in Electrical Engineering from Sepuluh November Institute of Technology, Indonesia, in 2001 and M. Eng. Degree from School of Electrical Engineering and Informatics, Indonesia in 2006. He got Ph.D. from the School of Electrical Engineering, Pusan a Ph.D. from the School of Electrical Engineering, Pusan National University, Korea. His research interests include robotics, robot vision, localization and navigation systems. Now he is a lecturer at Telkom University, and head of information Autonomous and Control System (INACOS).

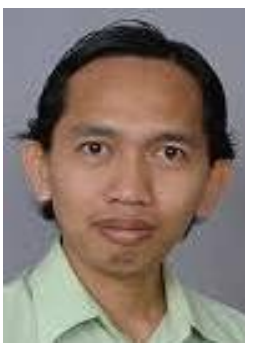

Rizki Ardianto Priramadhi received his Barchelor, Master and Doctor of Electrical Engineering from ITB, Indonesia. He currently works as lecturer in the Electrical Engineering Department of Telkom University, Bandung, Indonesia. 